\title{
Correspondence
}

\section{Autosomal dominant juvenile onset glaucoma affecting six generations in an Edinburgh family}

Sir, Crombie and Cullen reported a five generation pedigree of autosomal dominant juvenile onset glaucoma in

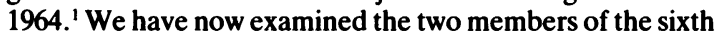
generation, both of whom have developed juvenile onset glaucoma, associated with abnormal drainage angle appearance. The two cases are the daughters of case V1 (as described previously ${ }^{1}$ ).

Case 1 presented to the Eye Department at age 21 years, complaining of coloured haloes around lights and contact lens intolerance. Intraocular pressure was $28 \mathrm{mmHg}$ in the right eye and $42 \mathrm{mmHg}$ in the left. Cup:disc ratios were 0.5 in the right eye, 0.6 in the left. Visual fields were full. Gonioscopy revealed open drainage angles with fine white lacey tissue and fine blood vessels. She had been examined at age 7 years because of the known family history of glaucoma. At that time intraocular pressures had been 14 $\mathrm{mmHg}$ in each eye, with normal optic discs.

Case 2 was examined at age 17 years, following the finding of glaucoma in her sister. She was asymptomatic. Intraocular pressure was $34 \mathrm{mmHg}$ in each eye, with a cup:disc ratio of 0.9 in the right eye and 0.8 in the left. Visual fields were full. Gonioscopy revealed open angles, with white lacey tissue and large blood vessels at the level of the trabecular meshwork in many areas. She had been examined at age 4 years, when the corneal diameters and optic disc appearances were normal.

The sixth generation of this family, along with member V2, as previously described, ' have been clearly demonstrated to have autosomal dominant juvenile onset glaucoma, with abnormal tissue in the drainage angles. Although the classification of juvenile onset glaucoma remains in dispute,,$^{23}$ the combination of features in this family justifies acceptance as a distinct disease entity.

Princess Alexandra Eye Pavilion,

B W FLECK Chalmers Street, Edinburgh EH3 9HA

J F CULLEN

\section{References}

1 Crombie AL, Cullen JF. Hereditary glaucoma. Occurrence in five generations of an Edinburgh family. Br J Ophthalmol 1964; 48: 143-7.

2 Leydhecker W. Simple glaucoma before the age of 30 years. Ophthalmologica 1979; 178: 32-6.

3 Goldwyn R, Waltman SR, Becker B. Primary open angle glaucoma in adolescents and young adults. Arch Ophthalmol $1970 ; 84: 579-82$.

\section{Book reviews}

Ophthalmology Annual: Nineteen eighty-six. Edited by ROBERT D. ReINECKE.. Pp. 264. £64.15. Appleton-Century-Crofts: Norwalk, Connecticut. 1986.

1985 obviously was not a year for major ophthalmological advances to judge by the contents of this book. It contains reviews of 13 assorted topics which vary in their quality, length, and content. They are written by separate authors and cover subjects which vary from chalazions and their treatment (nothing new here) to a review of cystoid macular oedema, retrolental fibroplasia, two chapters on intraocular lenses, thyroid eye disease, and others. No present ophthalmic publication is complete without a section on radial keratometry and this book is no exception, with the author concluding after quite a good chapter that RK will achieve greater acceptance in time. My feeling is that this slim volume may provide bedtime browsing material, but few people will miss anything if they do not read it.

D J SPALTON

Infectious Diseases of the Eye. By Gilbert Smolin, Khalid Tabbara, and John Whitcher.. Pp. 182. $£ 32 \cdot 00$. Williams and Wilkins: London. 1984.

This book, the latest and one of the better volumes in a series of handbooks in ophthalmology, is intended to provide the practising ophthalmologist with a concise and up-to-date account of infectious disorders of the eye and adnexae. The text is arranged on anatomical grounds in seven chapters with an introductory section largely given over to a pragmatic description of laboratory diagnosis. The format of most chapters comprises a brief description of the relevant anatomy, the symptomatology and manifestations of infectious disorders, and specific isolation techniques. Epidemiological considerations, causative agents, and the rationale and principles of prophylaxis and therapy are all dealt with in a reasonably comprehensive manner in most sections. The chapters devoted to microbial keratitis and endophthalmitis are particularly informative and well balanced, with sufficient attention paid to controversial issues, for example the role of vitrectomy in endophthalmitis. Throughout this volume the text is particularly well complemented by carefully selected black-and-white illustrations of excellent clarity and detail. My only major criticism is that in a number of sections the bibliography contains a disappointing number of references to the literature of the past five years which in some respects detracts from the overall value of the book.

Broadly speaking this is a well written treatise on infectious ocular disease which is both enjoyable to read and readily assimilated. The authors have achieved their stated intention to provide concise and comprehensive coverage of clinical ocular microbiology, and as such it is a welcome addition to the current ophthalmic literature. R J CoOLING 